ORIGINAL ARTICLE

\title{
Correlation of resistive index of main renal artery and inter-lobar artery with degree of hydronephrosis.
}

\author{
Huma Siddiq Baba', Muhammad Asif ${ }^{2}$, Muhammad Nawaz Anjum ${ }^{3}$
}

Article Citation: Baba HS, Asif M, Anjum MN. Correlation of resistive index of main renal artery and inter-lobar artery with degree of hydronephrosis. Professional Med J 2022; 29(3):407-414. https://doi.org/10.29309/TPMJ/2022.29.03.6486

\begin{abstract}
Objective: To study the correlation of resistive index of main renal artery and inter-lobar artery with degree of hydronephrosis. For the purpose of this study data collection was carried through different research works conducted previously regarding hydronephrosis and its effects on the resistivity index of renal arteries. Study Design: Systemic Review. Setting: Radiology Research Section, University of Lahore. Period: September 2018 to May 2020. Material \& Methods: Research was conducted with the help of keywords. One hundred and three articles were found at initial stage. A table was designed for data collection purpose including the information such as author of article, year of research, type of hydronephrosis, number of patients, and the resistive index of renal arteries. The data included both male and female patients of any age suffering from hydronephrosis of any origin and no area or time limitation was applied. Results: Pooling results of this systematic review depicts that the researchers conducted various researches addressing the cause of hydronephrosis, the effect of type of hydronephrosis on the resistive index, difference between resistivity index of obstructive and nonobstructive hydronephrosis, level of obstruction and its effect on RI of the renal artery, factors that influence RI other than renal in origin but not a single research conducted on human subject represents the correlation of different grades or degrees of hydronephrosis with either main renal artery or inter-lobar arteries. Out of 17 articles, 8 (47\%) articles discuss the resistive index for both obstructive and non-obstructive hydronephrosis while remaining 9 (53\%) articles discuss only the mean resistive index for the obstructed kidney. Conclusion: Although renal resistive index is the parameter which is influenced by a variety of other factors such as age of patient, plasma renin level, and the simultaneous presence of certain diseases like hypertension, cardiac diseases, diabetes mellitus, and renal disorders. The presence of any of these factors may rise the RI values even if there is no renal obstruction. Yet different research mainly shows that the values of $\mathrm{RI}$ are high i.e. $>0.70$ in case of obstructed kidney while generally the values of $\mathrm{Rl}$ are $<0.70$ in case of none obstructed kidney.
\end{abstract}

Key words: $\quad$ Hydronephrosis, Inter-Lobar Artery, Main Renal Artery, Resistive Index.

\section{INTRODUCTION}

The kidney has two main physiological parts; renal parenchyma and pelvicalyceal system. The renal parenchyma function is to produce urine and the pelvicalyceal system collects urine and sends urine into the ureter. Hydronephrosis is synonymous with dilatation of the pelvicalyceal system, and describes the renal swelling or dilatation occurring due to urine flow obstruction and its inability to drain into the bladder. ${ }^{1}$ There are different grading systems used to define the degree of hydronephrosis such as; Anterior Posterior Diameter of Renal Pelvis (APDRP), society for fetal urology (SFU) Grading System,
Radiology Grading System, urinary tract dilatation (UTD) Classification, and Onen Grading System. All of them have their own advantages, disadvantages and uses. ${ }^{2}$ Hydronephrosis is usually caused by another underlying illness or risk factor. It may occur due to renal calculi, congenital blockage, thrombus, tissue scaring, urinary tract infection, enlarged prostate, pregnancy, certain tumors or cancers such as that of bladder, cervix, colon or prostate. ${ }^{3}$ Urinary tract stones or calculus remains a chief health complaint all over the world. Patients having renal colic complaint are at $33 \%-68.3 \%$ risk of acute urinary tract obstruction either complete or partial
1. MBBS, DMRD, Senior Lecturer Radiology, University of Lahore.

2. MBBS, FCPS, FACS, MRCPS, Associate Professor Urology, ANMC

3. MBBS, FRCS, Professor Radiology, University of Lahore.
Correspondence Address:

Dr. Huma Siddiq Baba

House No. 116, Block M3, Street 3 Lack City, Lahore.

dr.huma.imran1@gmail.com

Article received on:

$24 / 03 / 2021$

Accepted for publication: 
which may give rise to hydroureteronephrosis. ${ }^{4}$

Color Doppler ultrasound is a non-invasive, economic, quick, easily available modality having no exposure to radiation for the assessment of kidneys. Renal anatomy, and pathologies such as hydronephrosis and its severity can be easily evaluated by color Doppler ultrasound. ${ }^{5}$ The renal arterial resistive index $(\mathrm{Rl})$ is a sonographic index of intra-renal arteries defined as (peak systolic velocity end-diastolic velocity)/peak systolic velocity. The resistive index can easily be calculated; but scanners can also automatically calculate $\mathrm{Rl}$ itself. The normal range is $0.50-0.70 .^{6}$

The resistive index $(\mathrm{Rl})$ is measured using spectral Doppler at the main renal artery, arcuate arteries or inter-lobar arteries. The renal resistive index is employed for studying vascular and renal abnormalities such as renal parenchymal in origin. But increasing evidence shows that the resistive index is a dynamic marker used to study systemic vascular properties. ${ }^{7}$ The literature reported resistive index sensitivity and specificity, $75.5 \%$ and specificity $92.5 \%$ respectively. ${ }^{8}$

Literature shows that the resistive index is influenced by many other factors such as the age of patient, level of renin in plasma, and the simultaneous presence of diabetes mellitus, hypertension, cardiac diseases, and variety of kidney disorders. The presence of any of these factors may rise the values of resistivity index even in there is no renal obstruction. ${ }^{9}$

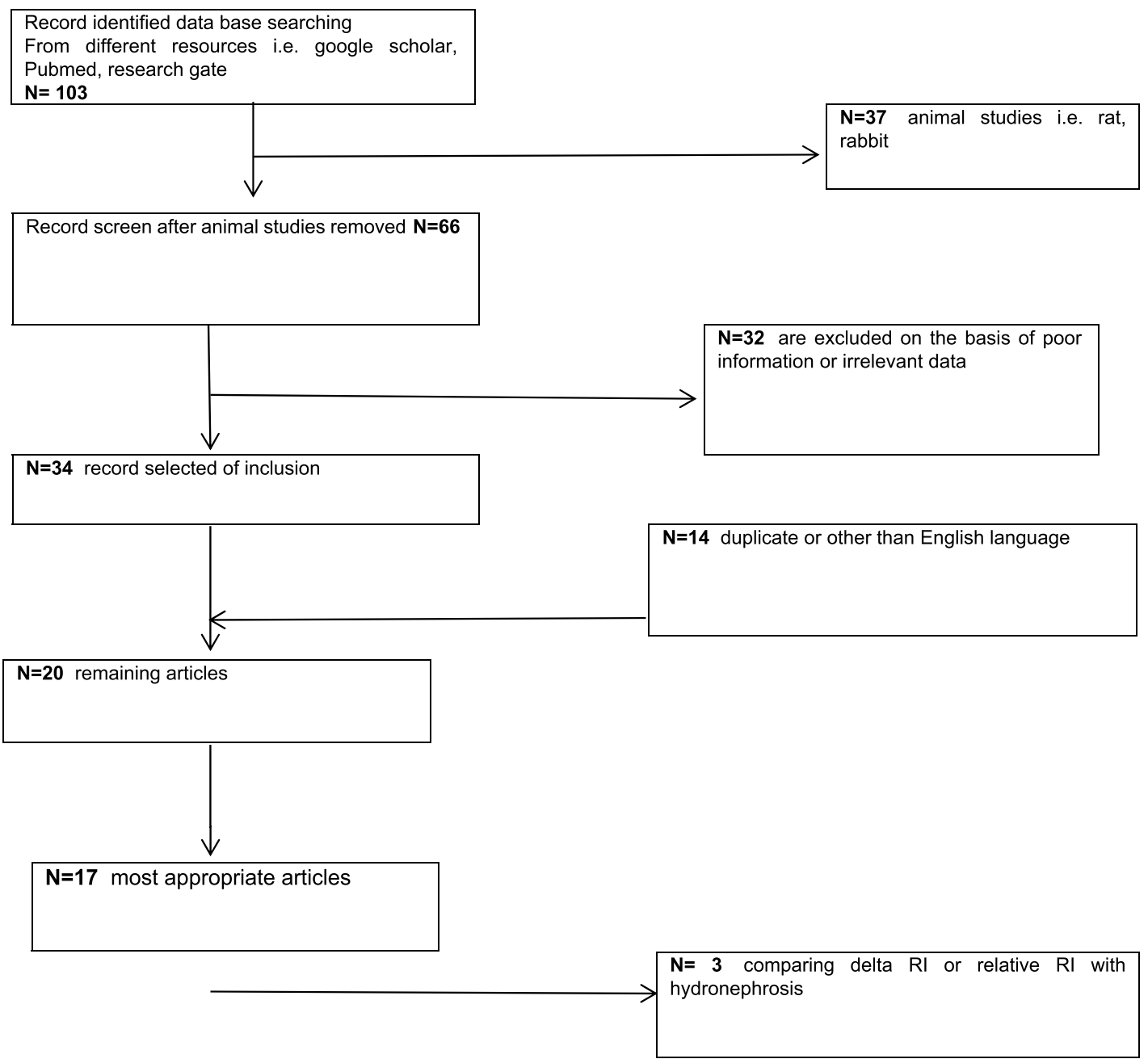

Chart. PRISMA chart. 


\section{MATERIAL \& MEDTHODS}

\section{OBJECTIVES}

The objective of this systematic review is to find the correlation of resistive index of main renal artery and inter-lobar artery with degree of hydronephrosis by exploring the relevant data from different studies conducted by other researchers by using ultrasound as a modality.

\section{Search Strategy}

For this study electronic articles were searched on Google scholar, PUB Med, online Willey library, Science Direct and Research Gate site for this systematic review. Keywords were included to find out the desired data. Mostly data was collected through keywords like resistive index of main renal artery, resistive index of interlobar renal artery, grades of hydronephrosis and its effect on resistive index, degrees of hydronephrosis and its effect on resistive index, relation of hydronephrosis with resistive index to search relevant articles. With the help of keywords, the title, abstract, aims and objectives, results and discussion were analyzed to extract the relevant data.

At the initial stage of gathering data, one hundred and two articles were found with selected keywords. In the first screening, 37 articles conducted on animals such as rabbits and rats taken as subject of study were removed from study. In next step, 14 more articles were excluded from study due to duplication or author language was other than English. In further screening 32 more articles were screened due to poor information, they emphasized on either hydronephrosis its reasons, grades, antenatal and postnatal comparison of hydronephrosis or factors influencing resistivity index other than hydronephrosis. 3 more articles were removed comparing resistive index ratio and delta $\mathrm{RI}$ with hydronephrosis. At the last stage, 17 articles were found to be the most appropriate one that fulfilled the inclusion criteria and had adequate data on this topic. Yet there was not a single article which provided the complete information required for the study.

\section{Inclusion Criteria}

Only those articles which comprise on relevant information of study type, values of resistive index for different types of renal hydronephrosis conditions such as obstructive or non-obstructive, hydronephrosis due to renal calculi or due to pregnancy, comparison of resistivity indexes for obstructive or non-obstructive hydronephrosis, severity or duration of hydronephrosis on resistive index were included for this research. Relevant articles without any time limitation were gathered.

\section{Exclusion Criteria}

Information in the form of posters, case, letters to the editors, and articles with copied information was excluded from this study. Articles which were written in other than English language were also not included for this research. On the behalf of keywordsonehundred and two articleswerefound. Majority of researches were done on the prenatal and postnatal comparison of hydronephrosis and the values of resistive index. So, all the studies which under took such comparative studies were excluded after screening. On the other hand the researches done on animal subject were also excluded in this study. The researches which were having inadequate information such as the effect of factors other than hydronephrosis on the resistive index are not included in this research. The evaluation of our selected data was further done into two phases first we select the data based on abstract and title. Secondly, we examine the inner text of articles and include if they were eligible to fill the inclusion criteria of our study.

\section{RESULTS}

Pooling results of this systematic review depicts that the researchers conducted various researches addressing the cause of hydronephrosis, the effect of type of hydronephrosis on the resistive index, difference between resistivity index of obstructive and non-obstructive hydronephrosis, level of obstruction and its effect on RI of the renal artery, factors that influence Rl other than renal in origin but not a single research conducted on human subject represents the correlation of different grades or degrees of hydronephrosis with either main renal artery or inter-lobar arteries resistive index. Out of 17 articles, $8(47 \%)$ articles 
discuss the resistive index for both obstructive and non-obstructive hydronephrosis while remaining 9 (53\%) articles discuss only the mean resistive index for the obstructed kidney. But the resistive index exceeds the normal limit $(>0.70)$ in case of obstructive hydronephrosis while in case of partial obstruction or non-obstructive hydronephrosis the $\mathrm{RI}$ values are variable and are within the normal limits $(<0.70)$.

\begin{tabular}{|c|l|c|c|}
\hline Sr\# & Researcher & Year & $\begin{array}{c}\text { Mean RI of Obstructed } \\
\text { Kidney }\end{array}$ \\
\hline 1 & Geavlete $^{10}$ & 2002 & 0.76 \\
\hline 2 & Ashraf $^{11}$ & 2009 & 0.70 \\
\hline 3 & Platt $^{12}$ & 1989 & 0.70 \\
\hline 4 & Detoledo $^{13}$ & 1996 & 0.70 \\
\hline 5 & Amin $^{14}$ & 2004 & 0.70 \\
\hline 6 & Hyder $^{15}$ & 2009 & 0.77 \\
\hline 7 & Onur $^{16}$ & 2007 & 0.69 \\
\hline 8 & Skokeir $^{17}$ & 2000 & 0.69 \\
\hline 9 & Sauvian $^{18}$ & 1989 & 0.70 \\
\hline
\end{tabular}

Table-I. Table showing the mean values of RI in case of obstructed kidney.
According to this graph two researchers concluded with the mean RI of 0.69 for obstructed kidney, 5 out of 9 researches showed that the mean $\mathrm{RI}$ was 0.70 while 1,1 research concluded that the mean $\mathrm{Rl}$ for obstructed kidney was 0.76 and 0.77 respectively.

The total number of articles was 8 . The range for obstructed and non-obstructed kidney was 0.14 and 0.07 respectively. The minimum values of $\mathrm{Rl}$ were 0.63 and 0.70 while maximum values were 0.70 and 0.84 , the mean value for obstructed and non-obstructed kidney were 0.7438 and 0.6675 respectively. The standerd deviation was 0.03284 and 0.05208 for non-obstructed and obstructed kidney respectively.

\begin{tabular}{|l|c|c|c|c|c|c|}
\hline & N & Range & Minimum & Maximum & Mean & Std. Deviation \\
\hline RI of obstructed Kidney & 9 & .08 & .69 & .77 & .7122 & .03032 \\
\hline Valid N & 9 & & & & \\
\hline
\end{tabular}

Table-II. Table showing descriptive statistics of the mean value of RI in case of obstructed kidney. The articles stating mean $R I$ were $n=9$, the range for these were 0.08 . The minimum and maximum values were 0.69 and 0.77 respectively. The mean value for the $\mathrm{RI}$ was 0.7122 while standard deviation was 0.03032 .

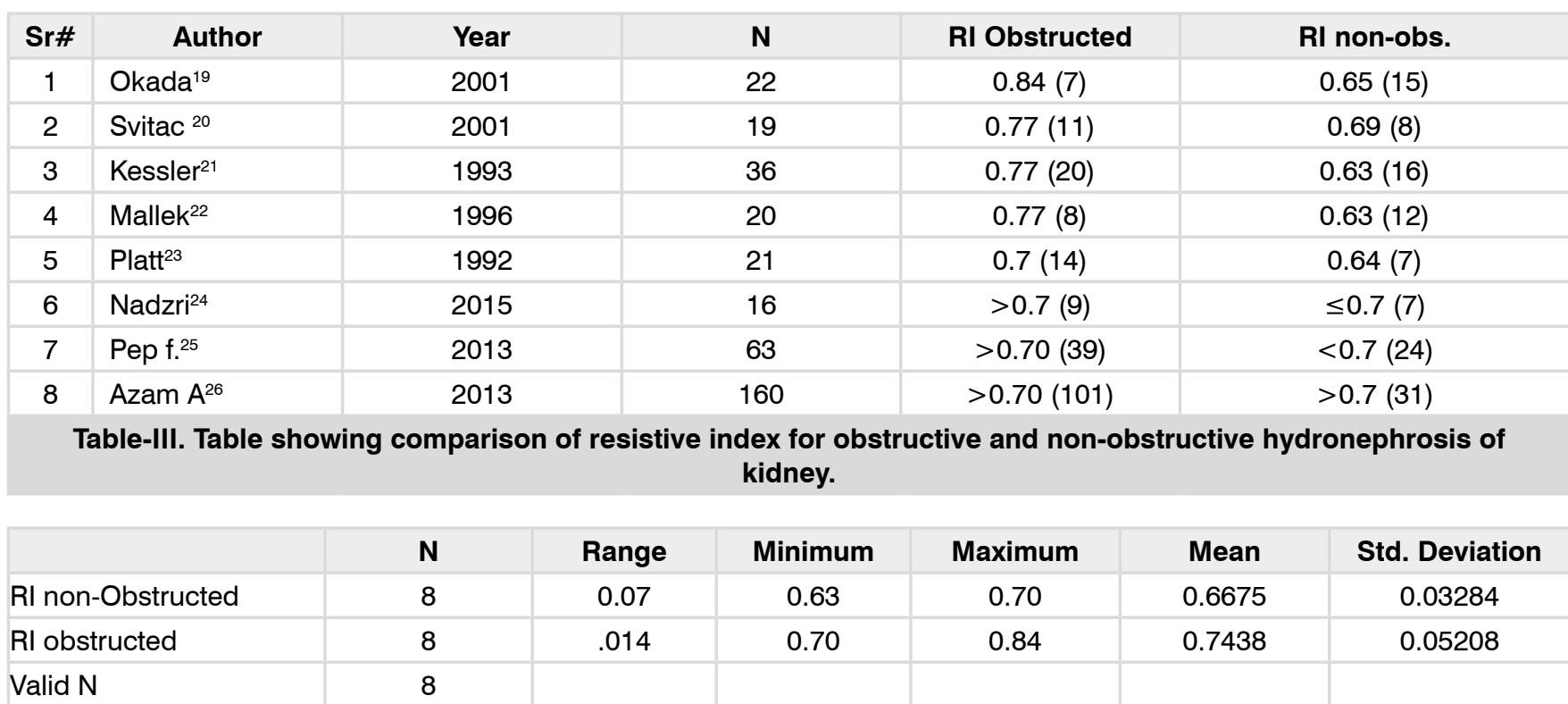

Table-IV. This table shows the discriptive statistics of the articles which studied the risistive index for both obstructed and non-obstructed kidney. 


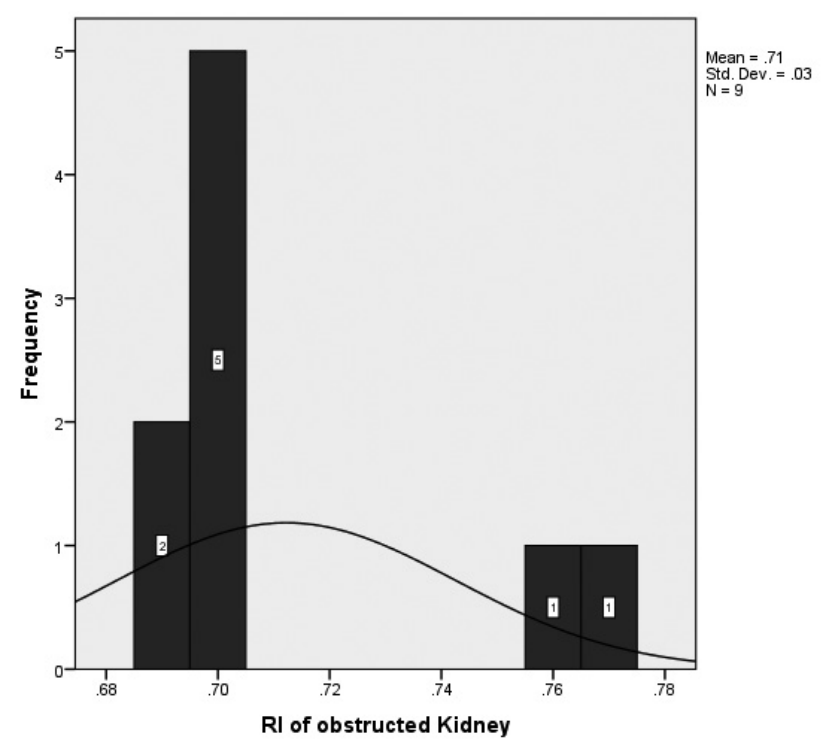

Figure-1. Figure representing the mean value of $\mathrm{RI}$ in case of obstructed kidney.

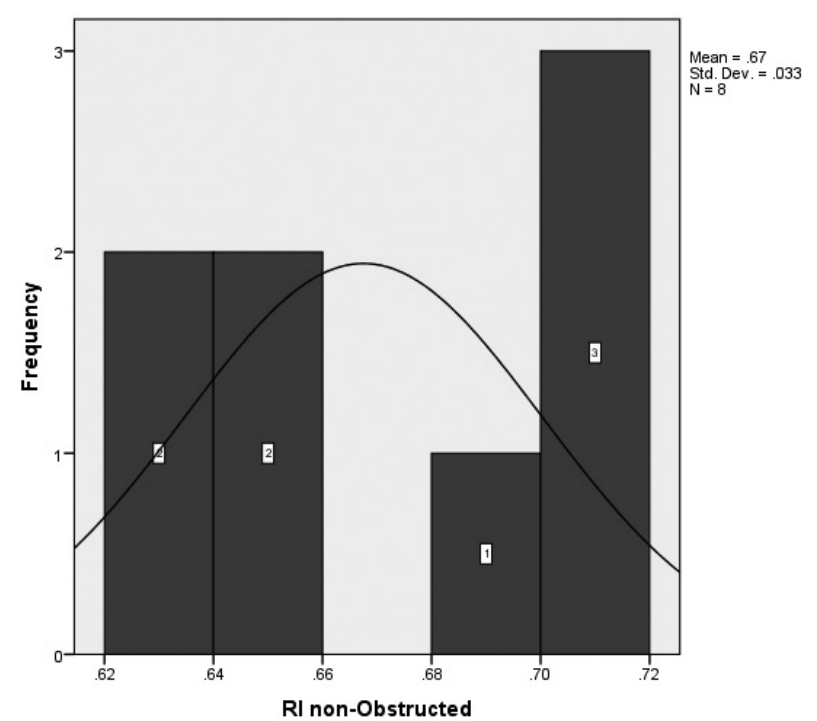

Figure-3. The figure is showing frequency of research articles for various values of $\mathrm{RI}$ in cases of nonobstructed hydronephrosis the mean for which was 0.67 and standard deviation $\mathbf{0 . 0 3 3}$

\section{DISCUSSION}

Hydronephrosis is defined as the dilatation of renal collecting system i.e. calyces, infundibula, and pelvis. The first line investigation for the renal collecting system is ultrasound. Ultrasound sensitivity and accuracy to access and categorize the hydronephrosis is good and it is also widely used to determine its major cause.

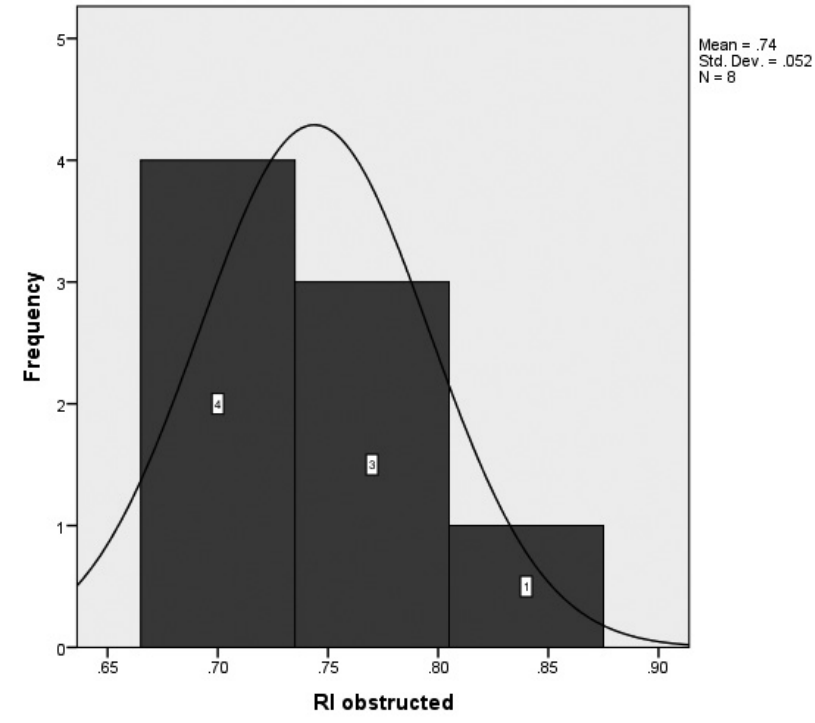

Figure-2. Figure showing the frequency and value of RI for above mentioned table. The number of selected articles were $n=8$, the value of mean $R I$ and standard deviation were 0.74 and 0.052 respectively.

An ultrasound machine uses acoustic wave to create an image of the kidney. Hydronephrosis is generally diagnosed through an ultrasound scan. Further testing may be required to find out the actual causes of condition.

Hydronephrosis is among the most common complication resulting from kidney obstructive diseases, if it is not treated, it may lead to severe complications consequences in acute or chronic kidney failure. The sonographic appearance categorize hydronephrosis into mild hydronephrosis, moderate hydronephrosis and severe hydronephrosis categories. Mild hydronephrosis is the most common $53 \%$, moderate hydronephrosis $30 \%$, severe $13 \%$. When the cause of hydronephrosis are analyzed they are different i.e. stones in ureters $31 \%$, renal stones $23 \%$, gestation $12 \%$, benign hypertrophy of prostate $11 \%{ }^{27}$ In $1 \%-5 \%$ of all gestations an antenatal hydronephrosis is diagnosed. ${ }^{28}$ The hydronephrosis prevalence is $10.3 \%$ in patients having history of organ prolapse in pelvic region. ${ }^{29}$

The renal resistivity index is calculated through the formula: (peak systolic velocity - end diastolic velocity)/peak systolic velocity, three consecutive readings are taken and its mean is calculated. The renal resistive index value $0.60 \pm 0.01$ 
(mean $\pm S D$ ) is generally taken as normal while most authors takes a value of 0.70 is as the upper normal threshold. ${ }^{30}$ There are many reports in the literature demonstrating that the color Doppler ultrasound for the measurement of $\mathrm{Rl}$ is helpful to diagnose acute obstruction of urinary tract in the patients having recent onset (6-48 h) in case of unilateral renal colic. ${ }^{31}$ The $\mathrm{RI}$ can be easily calculated; or can be calculated automatically by the ultrasound machine itself. As the resistive index is directly correlated to pressure inside the renal collecting system, so an acute obstruction in the urinary tract can increase the value of resistive index. Certainly, the excretory ducts dilatation causes progressive pressure on the renal parenchyma and the vessels, so the resistance inside these vessels increase. ${ }^{32}$

In the 1980s Platt ${ }^{33}$ and Sauvain ${ }^{34}$ reported that resistive index greater than 0.70 indicated acute ureteral obstruction; since then, many studies carried on human and animal's subjects had confirmed the finding and credited high sensitivity and specificity of the color Doppler ultrasound in the measurement of the resistive index. ${ }^{35}$ The resistive index is influenced by a variety of factors, such as the age of patient, levels of renin in plasma, the concomitant incidence of diabetes, hypertension, cardiac disease, and a variety of renal disorders. The presence of these factors can raise the value of resistivity index even if there is no renal obstruction. ${ }^{36}$ In agreement with the findings of Shokeir ${ }^{37}$ and other authors, no significant correlation was found between the $\mathrm{RI}$ and the level of ureteral obstruction, whereas de Toledo $^{38}$ reported that proximal obstructions were associated with higher Rls than distal obstructions. Other authors have observed a relation between the $\mathrm{Rl}$ and the magnitude of dilation. ${ }^{39}$ In a cohort conducted by Piazzese et al., ${ }^{40}$ the $\mathrm{Rl}$ exhibited no significant correlation with the degree of dilation or with the duration of the colic. No significant correlation was found between $\mathrm{mRl}$ values and the level of ureteral obstruction, the degree of dilatation, the size of the obstructing calculus ( $\leq 6 \mathrm{~mm}$ in 11 cases, $>6 \mathrm{~mm}$ in 18), or the duration of the pain (range 4-38 h).

\section{CONCLUSION}

Renal resistive index is the parameter which is influenced by a variety of other factors such as age of patient, plasma renin level, and the simultaneous presence of certain diseases like hypertension, cardiac diseases, diabetes mellitus, and renal disorders. The presence of any of these factors may raise the $\mathrm{Rl}$ values even if there is no renal obstruction. Yet different research shows that the values of $\mathrm{Rl}$ are high i.e. $>0.70$ in case of obstructed kidney while generally the values of $\mathrm{RI}$ are $<0.70$ in case of non-obstructed kidney. There is much data present in literature discussing antenatal and postnatal hydronephrosis, the values of $\mathrm{Rl}$ for obstructed hydronephrosis, $\mathrm{Rl}$ for non-obstructed hydronephrosis but further research is required to determine the correlation of different grades of hydronephrosis on the resistivity index of main renal artery and interlobar artery of kidney.

Copyright $(11$ June, 2021.

\section{REFERENCES}

1. Riccabona M. Assessment and management of newborn hydronephrosis. World journal of urology. 2004 Jun $1 ; 22(2): 73-8$.

2. Onen A. Grading of hydronephrosis: An ongoing challenge. Frontiers in Pediatrics. 2020; 8. (grades of HN)

3. Patel K, Batura D. An overview of hydronephrosis in adults. British Journal of Hospital Medicine. 2020 Jan 2; 81(1):1-8.

4. Govindaraju S, Ettappan A. Renal resistive index as a predictor of acute hydronephrosis in patients with renal colic. Journal of Evolution of Medical and Dental Sciences. 2018 May 28; 7(22):2678-81.

5. de Bessa Júnior J, Dénes FT, Chammas MC, Cerri L, Monteiro ED, Buchpiguel CA, Cerri GG, Srougi M. Diagnostic accuracy of color Doppler sonographic study of the ureteric jets in evaluation of hydronephrosis. Journal of pediatric urology. $2008 \mathrm{Apr}$ $1 ; 4(2): 113-7$.

6. Pepe P, Motta L, Pennisi M, Aragona F. Functional evaluation of the urinary tract by color-Doppler ultrasonography (CDU) in 100 patients with renal colic. Eur J Radiol 2005; 53: 131-5.

7. Boddi M, Natucci $F$, Ciani $E$. The internist and the renal resistive index: Truths and doubts. Internal and emergency medicine. 2015 Dec 1; 10(8):893-905. 
8. Alshoabi SA. Association between grades of Hydronephrosis and detection of urinary stones by ultrasound imaging. Pakistan journal of medical sciences. 2018 Jul; 34(4):955. (definition,SFU,.

9. Sayani R., Ali M., Shazlee K., Hamid R.S., Hamid K. Functional evaluation of the urinary tract by duplex Doppler ultrasonography in patients with acute renal colic. Int J Nephrol Renovasc Dis. 2012; 5:15-21.

10. Geavlete P, Georgescu D, Cauni V, Nita G. Value of duplex doppler ultrasonography in renal colic. Eur Urol 2002; 41: 71-8.

11. Ashraf Z, Mansoor T, Ashai M, Ahmad I, Lateef W. Duplex Doppler ultrasonography: An excellent initial investigation in obstructive uropathy. The Internet Journal of Surgery. 2009; 20: 11.

12. Platt JF, Rubin JM, Ellis JH, DiPietro MA. Duplex Doppler US of the kidney; differentiation of obstructive from nonobstructive dilatation. Radiology 1989; 171: 515-7.

13. deToledo LS, Martinez-Berganza AT, Cozcolluela CR, de Gregorio Ariza MA, Cortina PP, Saldias LR. Dopplerduplex ultrasound in renal colic. Eur J Radiol 1996; 23: $143-8$.

14. Amin MU, Ghaffar A. Intrarenal and intravesical color Doppler sonography in patients with acute renal colic. J Surg Pakistan 2004; 9: 40-2.

15. Hyder RR, Khan Y, Umar M, Aziz T, Saeed M. The usefulness of inter-renal resistive index difference in diagnosing acute unilateral ureteric obstruction due to calculus. Pak Armed Forces Med J 2009; 59: 211

16. Onur MR, Cubuk M, Andic C, Kartal M, Arslan G. Role of resistive index in renal colic. Urol Res. 2007; 35: 307-12.

17. Shokeir AA, Mahran MR, Abdulmaaboud M. Renal colic in pregnant women: Role of renal resistive index. Urology 2000; 55: 344-7.

18. Sauvain JL, Pierrat V, Chambers R, Bui Xuan P, Palascak $P$, Boursheid D, et al. Echography and pulsed Doppler of the arteries of the renal parenchyma in obstructive syndromes and dilatation of the excretory cavities of the kidney. J Radiol 1989; 70: 389-98.

19. Okada T, Yoshida H, Iwai J, et al. Pulsed Doppler sonography of the hilar renal artery: Differentiation of obstructive from nonobstructive hydronephrosis in children. J Pediatr Surg. 2001; 36(3): 416-20.

20. Svitac J, Zibolen M, Kliment J, et al. Renal Doppler ultrasonography in infants with hydronephrosis. Int Urol Nephrol. 2001; 33(3): 431-3.
21. Kessler RM, Quevedo H, Lankau CA, et al. Obstructive vs nonobstructive dilatation of the renal collecting system in children: distinction with duplex sonography. AJR Am J Roentgenol. 1993; 160(2): 3537.

22. Mallek R, Bankier AA, Etele-Hainz A, et al. Distinction between obstructive and nonobstructive hydronephrosis: Value of diuresis duplex Doppler sonography. AJR Am J Roentgenol. 1996; 166(1): 1137.

23. Platt JF. Duplex Doppler evaluation of native kidney dysfunction: Obstructive and nonobstructive disease. AJR Am J Roentgenol. 1992; 158(5): 1035-42.

24. Nadzri M, Hing EY, Hamzaini AH, Faizah MZ, Abaziz A, Kanaheswari Y, Zulfiqar MA. Renal doppler assessment in differentiating obstructive from non-obstructive hydronephrosis in children. The Medical journal of Malaysia. 2015 Dec 1; 70(6):346-50.

25. Pepe F, Pepe P. Color Doppler ultrasound (CDU) in the diagnosis of obstructive hydronephrosis in pregnant women. Archives of gynecology and obstetrics. 2013 Sep 1; 288(3):489-93.

26. Azam A, Arfan-ul-Haq MA, Beg MA. Role of renal arterial resistive index (RI) in obstructive uropathy. $J$ Pak Med Assoc. 2013 Dec 1; 63(12):1511-.

27. Abdelmaboud SO, Gameraddin MB, Ibrahim T, Alsayed A. Sonographic evaluation of hydronephrosis and determination of the main causes among adults. Int $\mathrm{J}$ Med Imaging. 2015; 3(1):1-5.

28. Leers, Cendron M, Kinnamon DD, Nguyen HT. Antenatal hydronephrosis as a predictor of postnatal outcome: A meta-analysis. Pediatrics. 2006 Aug 1; 118(2):58693.

29. Hui SY, Chan SC, Lam SY, Lau TK, Chung KH. A prospective study on the prevalence of hydronephrosis in woman with pelvic organ prolapse and their outcomes after treatment. International urogynecology journal. 2011 Dec 1; 22(12):1529-34.

30. Tublin ME, Bude RO, Platt JF. The resistive index in renal Doppler sonography: Where do we stand?. American Journal of Roentgenology. 2003 Apr; 180(4):885-92.

31. Shokeir A.A., Abdulmaaboud M. Resistive index in renal colic: a prospective study. BJU Int. 1999; 83:378-382.

32. Rawashdeh Y.F., Djurhuus J.C., Mortensen J., Hørlyck A., Frokiaer J. The intrarenal resistive index as a pathophysiological marker of obstructive uropathy. J Urol. 2001; 165:1397-1404. 
33. Platt J.F., Rubin J.M., Ellis J.H. Acute renal obstruction: evaluation with intrarenal duplex Doppler and conventional US. Radiology. 1993; 186:685-688.

34. Sauvain J.L., Pierrat V., Chambers R., Bui Xuan P., Palascak P., Boursheid D. Echography and pulsed Doppler of the arteries of the renal parenchyma in obstructive syndromes and dilatation of the excretory cavities of the kidney. J Radiol. 1989; 70:389-398.

35. Kavakli H.S., Koktener A., Yilmaz A. Diagnostic value of renal resistive index for the assessment of renal colic. Singapore Med J. 2011; 52:271-273.

36. Sayani R., Ali M., Shazlee K., Hamid R.S., Hamid K. Functional evaluation of the urinary tract by duplex Doppler ultrasonography in patients with acute renal colic. Int J Nephrol Renovasc Dis. 2012; 5:15-21.
37. Shokeir A.A., Abdulmaaboud M. Prospective comparison of nonenhanced helical computerized tomography and Doppler ultrasonography for the diagnosis of renal colic. J Urol. 2001; 165:1082-1084.

38. de Toledo L.S., Martinez-Berganza Asensio T., Cozcolluela Cabrejas R., de Gregorio Ariza M.A., Pardina Cortina P., Ripa Saldias L. Doppler-duplex ultrasound in renal colic. Eur J Radiol. 1996; 23:143-148.

39. Haroun A. Duplex Doppler sonography in patients with acute renal colic: Prospective study and literature review. Int Urol Nephrol. 2003; 35:135-140.

40. Piazzese EM, Mazzeo Gl, Galipò S, Fiumara F, Canfora $\mathrm{C}$, Angiò LG. The renal resistive index as a predictor of acute hydronephrosis in patients with renal colic. Journal of ultrasound. 2012 Dec 1; 15(4):239-46.

\begin{tabular}{|c|l|l|l|}
\hline \multicolumn{3}{|c|}{ AUTHORSHIP AND CONTRIBUTION DECLARATION } \\
\hline No. & \multicolumn{1}{|c|}{ Author(s) Full Name } & \multicolumn{1}{|c|}{ Contribution to the paper } & Author(s) Signature \\
\hline 1 & Huma Siddiq Baba & Discussion, References. \\
\hline 2 & Muhammad Asif & $\begin{array}{l}\text { Study design, Patients } \\
\text { Selection. }\end{array}$ \\
\hline 3 & Muhammad Nawaz Anjum & \begin{tabular}{l} 
Topic Selection. \\
\hline
\end{tabular} \\
\hline
\end{tabular}

